\title{
Effect of Heat stable Carbetocin vs Oxytocin for Preventing Postpartum Haemorrhage on Post Delivery Hemoglobin- A Randomized Controlled Trial
}

Sunil S Vernekar ( $\nabla$ drsunilsvernekar@gmail.com )

Jawaharlal Nehru Medical College https://orcid.org/0000-0002-0635-8041

Swati S Goudar

Amrita Institute of Medical Sciences and Research Centre: Amrita Institute of Medical Sciences

Mrityunjay C Metgud

JN Medical College: Jawaharlal Nehru Medical College

Yeshita V Pujar

JN Medical College: Jawaharlal Nehru Medical College

Manjunath S Somannavar

J N Institute of Medical Sciences: Jawaharlal Nehru Institute of Medical Sciences

Gilda Piaggio

Statistika Consultoria, Campinas, Sao Paulo, Brazil

José Ferreira de Carvalho

Statistika Consultoria, Campinas, Sao Paulo, Brazil

Amit Revankar

JN Medical College: Jawaharlal Nehru Medical College

Fernando Althabe

Reproductive Health Research, World Health Organization, Geneva, Switzerland

Mariana Widmer

Department of Sexual and Reproductive Health and Research, World Health Oragnization, Geneva, Switzerland

Ahmet Metin Gulmezoglu

Concept Foundation, Geneva, Switzerland

Shivaprasad S Goudar

JN Medical College: Jawaharlal Nehru Medical College

\section{Research}

Keywords: Post-partum haemorrhage, heat-stable carbetocin, post-delivery haemoglobin, uterotonics, oxytocin

Posted Date: May 19th, 2021

DOI: https://doi.org/10.21203/rs.3.rs-520884/v1

License: (9) (1) This work is licensed under a Creative Commons Attribution 4.0 International License. Read Full License

Version of Record: A version of this preprint was published at The Journal of Maternal-Fetal \& Neonatal Medicine on November 11th, 2021. See the published version at https://doi.org/10.1080/14767058.2021.2001799. 


\section{Abstract}

Background

Post-partum haemorrhage is one of the major causes of maternal mortality in low-and middle-income countries. Oxytocin is the first choice uterotonic for the PPH prevention but it requires cold storage. Heat stable carbetocin appears to be a promising agent for the prevention of PPH. The present study was an ancillary to the WHO CHAMPION Trial conducted to compare the effect of heat-stable carbetocin $100 \mu \mathrm{g}$ IM versus oxytocin $10 \mathrm{IU}$ IM on post-delivery hemoglobin level in one of the participating facilities in India.

Methods

This was a nested randomized controlled trial designed to compare the effect of heat-stable carbetocin $100 \mu \mathrm{g}$ IM versus oxytocin $10 \mathrm{IU} I \mathrm{IM}$, administered within one minute of vaginal delivery of the baby for prevention of postpartum haemorrhage, on post-delivery 48-72 hours hemoglobin level, adjusted for pre-delivery hemoglobin level. 1,799 women from one hospital in India participated in this study.

Results

Pre-delivery hemoglobin and postpartum blood loss were not significantly different between carbetocin and oxytocin. Postdelivery hemoglobin, unadjusted or adjusted for pre-delivery hemoglobin, was slightly lower for carbetocin compared to oxytocin. The drop in hemoglobin was slightly higher for carbetocin, although the difference was very small $(1.2 \mathrm{~g} / \mathrm{dL}$ for carbetocin, 1.1 $\mathrm{g} / \mathrm{dL}$ for oxytocin). The proportion of participants with a drop in hemoglobin of $2 \mathrm{~g} / \mathrm{dL}$ or more, adjusted for pre-delivery hemoglobin, was higher for carbetocin $(\mathrm{RR}=1.29,95 \% \mathrm{Cl} 1.02$ to 1.63$)$. From the regression coefficients it can be derived that post-delivery hemoglobin, adjusted for pre-delivery hemoglobin, decreases on average $0.12 \mathrm{~g} / \mathrm{dL}$ for each $\mathrm{dL}$ of blood lost, for the two treatments combined.

Conclusions

The present ancillary study showed that intramuscular administration of $100 \mu \mathrm{g}$ of heat stable carbetocin can result in a slightly lower post-delivery hemoglobin, slightly higher drop and higher percentage of women having a drop of $2 \mathrm{~g} / \mathrm{dL}$ or larger, compared to $10 \mathrm{IU}$ of oxytocin, but these differences are not clinically relevant.

Study registration

The trial was registered with Clinical Trial Registry of India CTRI/2016/06/006996.

\section{Plain English Summary}

This is an ancillary study of the WHO CHAMPION trial conducted at one of the six participating sites in India. We collected data on pre and post-delivery hemoglobin levels during the period of 12 months in this study. The primary outcome was post-delivery 48-72 hours hemoglobin. The secondary outcome was the proportion of women with a drop in post-delivery hemoglobin $\geq 2$ $\mathrm{g} / \mathrm{dl}$ after $48-72$ hours of delivery.

Out of 1799 women recruited in the study, 890 in the HS carbetocin group and 889 in the oxytocin group were analysed. Baseline characteristics of women were similar for the two treatment groups. Post-delivery hemoglobin was slightly lower for carbetocin compared to oxytocin. Correspondingly, proportion of participants with a drop in hemoglobin of $2 \mathrm{~g} / \mathrm{dL}$ or more was slightly higher for carbetocin. However, the magnitude of these differences was not clinically relevant.

Despite the slightly higher, but clinically insignificant, drop in post-delivery haemoglobin for HS carbetocin compared to oxytocin, the former offers advantage in being heat stable. Accurate measurement of blood loss and timely diagnosis and management can prevent avoidable morbidity and mortality associated with cases of severe post-partum haemorrhage. Based on results from the present study, measurement of drop in hemoglobin might be eventually used as a proxy for post-partum blood loss, provided 
further studies are conducted to shed more light on other individual factors that can improve individual prediction of blood loss, for assessing the efficacy of intervention for prevention and treatment of post-partum hemorrhage.

\section{Background}

Maternal mortality continues to be unacceptably high and in 2017, about 295,000 women died during and following pregnancy and childbirth. Almost all of these deaths occurred in low-resource settings, and most could have been prevented [1]. In 2015, United Nations adopted the Sustained Development Goals which aims at improving maternal health by reducing the global maternal mortality ratio to less than 70 per 100,000 livebirths by 2030 [1, 2]. Postpartum haemorrhage (PPH) is one of the major causes of maternal mortality in low- and middle-income countries. PPH affects approximately $5 \%$ of all women who give birth [3]. It is associated with nearly one-fourth of all maternal deaths globally and uterine atony is the most common cause of PPH [3]. PPH is commonly defined as a blood loss of $500 \mathrm{ml}$ or more within 24 hours after birth, while severe PPH is defined as a blood loss of $1000 \mathrm{ml}$ or more within the same timeframe. The majority of deaths due to PPH could be avoided through the use of prophylactic good quality uterotonics during the third stage of labour and by timely and appropriate management. WHO recommendations, updated in 2018, mention five effective drugs for the prevention of PPH namely oxytocin, carbetocin, misoprostol, ergometrine/ methylergometrine, and oxytocin with ergometrine fixed-dose combination [3, 4]. Oxytocin (IM/IV, 10 $\mathrm{IU}$ ) is recommended as the uterotonic drug of choice [3]. The use of heat-stable (HS) carbetocin has been recommended for the prevention of PPH in settings where oxytocin is unavailable (or its quality cannot be guaranteed) and where the cost of HS carbetocin is comparable to other effective uterotonics $[3,5,6]$. HS carbetocin is a long-acting synthetic agonist analogue of the human oxytocin $[7,8,9]$.

The World Health Organization conducted the WHO CHAMPION trial which was a phase III, randomized, double-blind, active controlled, multinational, multicentre, non-inferiority trial comparing the effectiveness of HS carbetocin with oxytocin for the prevention of postpartum haemorrhage during the third stage of labour in women delivering vaginally. The trial methods and results are described in detail elsewhere [10,11].

Although measured postpartum blood loss has been used as the primary outcome in a number of trials assessing the efficacy of strategies for prevention and treatment of PPH, post-delivery hemoglobin and decline from pre-delivery level have been regarded as more appropriate alternatives because they are theorized to be stronger indicators of risk for shock and death than postpartum blood loss [12]. Secondary analysis of data from three multi country randomized trials done by Anger $\mathrm{H}$ showed that there was a correlation between the blood loss after delivery and post-partum drop in hemoglobin They also found that the relation was not significant in cases where the blood loss was below $500 \mathrm{ml}$ and was significant when the blood loss was more than $1000 \mathrm{ml}[13,14]$. Mean drop in pre-to-post hemoglobin of $2 \mathrm{~g} / \mathrm{dl}$ or more is considered as a clinically important value to assess the correlation between blood loss and post-partum drop in haemoglobin in previous studies $[12,15,16]$. There are no studies assessing the effect of heat stable carbetocin for prevention of postpartum hemorrhage in low risk vaginal deliveries with post-delivery hemoglobin as the primary outcome. Even the large heat stable carbetocin trial coordinated by WHO has not incorporated post-delivery hemoglobin as an end point for assessing the efficacy of heat stable carbetocin. Hence, we conducted a nested randomized controlled study to compare the effect of heat-stable carbetocin $100 \mu \mathrm{g}$ IM versus oxytocin 10 IU IM on post-delivery hemoglobin level in one of the participating facilities in India.

\section{Methods}

This is an ancillary study of the WHO CHAMPION trial which collected data on pre and post-delivery hemoglobin levels during the period of 12 months. The primary outcome was post-delivery 48-72 hours hemoglobin. The secondary outcome was the proportion of women with a drop in post-delivery hemoglobin $\geq 2 \mathrm{~g} / \mathrm{dl}$ after $48-72$ hours of delivery [11].

The WHO CHAMPION trial was a randomized, double-blind, non-inferiority trial comparing the effectiveness of HS carbetocin with oxytocin for the prevention of PPH after vaginal birth. The trial methods and results are described in detail elsewhere [11]. This ancillary study was conducted in one of the six participating sites in India, and it consisted of including the additional measurement of pre- and post-delivery hemoglobin to the WHO CHAMPION protocol. Design and procedures are the ones described in the main study [11]. 
After initial clinical assessment of women presenting for delivery to the KLES Dr Prabhakar Kore Charitable Hospital \& Medical Research Center, Belgaum, a written informed consent was taken separately for the ancillary study along with the consent for the main trial.

Pre-delivery hemoglobin of each participant was recorded before she was randomized to the main trial. Estimation of hemoglobin was done using the HemoCue $\mathrm{Hb} 301$ with the technology of absorbance measurement of whole blood at $\mathrm{Hb} / \mathrm{HbO} 2$ isobestic point with a cuvette. Under aseptic conditions, $0.5 \mathrm{ml}$ of the capillary blood was collected after finger prick with a sterile lancet and placed on the cuvette. The time required by the hemoglobinometer for the hemoglobin estimation was approximately 10 seconds. Hemoglobin values were recorded on a form specifically designed for this study.

During the second stage of labour when vaginal delivery was imminent, eligible women were randomized to receive either oxytocin $10 \mathrm{IU}$ IM or HS carbetocin $100 \mu \mathrm{g}$ IM based on the random allocation sequence generated centrally at WHO Headquarters (the CHAMPION trial coordination centre) using computer-generated random numbers. During the third stage of labour women received the randomly assigned treatment, and blood loss was measured for one hour or two hours if bleeding continued after the first hour [17].

Post-delivery hemoglobin was measured using the same standard procedure used for estimation of pre-delivery hemoglobin between $48-72$ hours postpartum.

The present study was approved by JNMC Institutional Ethics Committee for Human Subjects. The trial was registered with Clinical Trial Registry of India CTRI/2016/06/006996.

\section{Statistical analyses}

The main analysis was conducted with the modified intention-to-treat population (as defined in Widmer et al 2018).

Descriptive statistics were calculated for characteristics of women and those of babies at birth. The number of participants, number of events and percentages in each category were calculated for the categorical variables. Number of participants, median and interquartile range (IQR) were calculated for the numeric variables.

Univariate analyses were conducted with the variables: pre-delivery hemoglobin, post-delivery haemoglobin, the drop from predelivery to post-delivery hemoglobin, and blood loss, to compare the treatments, using analysis of variance techniques. The statistical distribution of the variables was examined to decide whether a transformation was needed. The difference of means was used if the distribution was close to normal. In the case of blood loss, the distribution was asymmetric and the logarithmic transformation was used.

The primary outcome, post-delivery hemoglobin, was analysed using analysis of covariance to compare treatments, with predelivery hemoglobin as covariate to adjust the post-delivery hemoglobin for possible differences in baseline values (Model 1). Analysis of covariance is the preferred technique compared to the analysis of post-pre-difference [18]. Adjusted means of postdelivery hemoglobin were calculated, with $95 \%$ confidence intervals.

Regression analysis was used to assess the association of post-delivery hemoglobin and blood loss volume between the treatments (Model 2). This association was explored by including an interaction term of blood loss by arm in the model in order to allow the treatment regression lines to have different slopes (Model 3). The association between post-delivery hemoglobin and blood loss was quantified by the treatment-specific regression coefficients

The proportion of women with a drop in post-delivery hemoglobin of $2 \mathrm{~g} / \mathrm{dl}$ or more from pre-delivery hemoglobin was calculated for each treatment and compared using relative risk (RR) with $95 \%$ confidence intervals and risk difference with $95 \%$ confidence intervals. Both unadjusted and adjusted analysis for pre-delivery hemoglobin were conducted.

\section{Results}


The Belgaum site participated in the main study- CHAMPION Trial and recruited 1799 women for this sub-study. The trial profile is shown in Figure 1. After randomization, two women underwent caesarean section in each group. After excluding the missing values, the participants included in final analysis were 890 in the HS carbetocin group and 889 in the oxytocin group.

Baseline characteristics of women at trial entry, characteristics of women at labour and characteristics of babies at birth were similar for the two treatment groups (Table 1).

The mean pre-delivery haemoglobin and median post-partum blood loss as shown in Table 2 were similar across the treatment groups. For post-delivery hemoglobin unadjusted analysis the mean was slightly lower for carbetocin compared to oxytocin $(0.128 \mathrm{~g} / \mathrm{dl}$ lower, $\mathrm{p}$-value=0.0432). The drop in hemoglobin between pre-delivery and post-delivery was slightly higher for carbetocin ( $p$-value=0.0786). The results of the adjusted analyses for post-delivery haemoglobin (Model 1 ) are shown in Table 3. The adjustment for pre-delivery hemoglobin showed similar results to the unadjusted analysis (similar point estimate for the difference between treatments in post-delivery hemoglobin means and p-value=0.0334). Additionally, adjusting for blood loss (Model 2) did not change the results.

From the regression coefficients (Model 3, see Appendix) it can be derived that post-delivery hemoglobin, adjusted for pre-delivery hemoglobin, decreases on average $0.09 \mathrm{~g} / \mathrm{dL}$ for each $\mathrm{dL}$ of blood lost for carbetocin, and $0.14 \mathrm{~g} / \mathrm{dL}$ for each $\mathrm{dL}$ of blood lost for oxytocin group. However, the difference of these coefficients was not significant ( $p$-value $=0.2171$ for the interaction blood loss by treatment group). Therefore, there is no evidence that the decrease in post-delivery hemoglobin with blood loss is different between the treatment groups as shown in Figure 2.

A drop of $\geq 2 \mathrm{~g} / \mathrm{dL}$ in hemoglobin from pre-delivery to post-delivery after $48-72$ hours of delivery was seen in $27.9 \%$ of women in carbetocin group compared to $24.1 \%$ in the oxytocin group as shown in Table 4 . The relative risk of having this event among women receiving carbetocin, compared to women receiving oxytocin, was 1.16 ( $95 \% \mathrm{Cl} 0.99$ to 1.36 ) in the unadjusted analysis, not attaining significance at $5 \%(p$-value=0.0682). When adjusted for pre-delivery hemoglobin, the relative risk was $1.29(95 \% \mathrm{Cl}$ 1.02 to 1.63 ), significant at $5 \%$ (p-value $\geq 0.0337$ ).

\section{Discussion}

In the present ancillary study, we were able to assess the effect of HS carbetocin compared to that of oxytocin on the postdelivery (48-72 hours) hemoglobin and on the drop in hemoglobin between pre-delivery and post-delivery hemoglobin. There was a drop in hemoglobin between pre-delivery and post-delivery of the order of $1 \mathrm{~g} / \mathrm{dL}$, and there was no evidence of difference in this drop between HS carbetocin $(1.2 \mathrm{~g} / \mathrm{dL})$ and oxytocin $(1.1 \mathrm{~g} / \mathrm{dL})$ ( $\mathrm{p}$-value=0.0786). Post-delivery hemoglobin, adjusted for predelivery hemoglobin and blood loss, was marginally lower for HS carbetocin compared to oxytocin ( $0.13 \mathrm{~g} / \mathrm{dL}$ lower), statistically significant but not clinically relevant. Our study showed that the decrease in post-delivery hemoglobin for each $\mathrm{dL}$ of blood lost $(0.09 \mathrm{~g} / \mathrm{dL}$ for carbetocin and $0.14 \mathrm{~g} / \mathrm{dL}$ for oxytocin on average), adjusted for pre-delivery hemoglobin was not significantly different between two groups. The overall negative association between post-delivery hemoglobin and blood loss was statistically significant $(p<0.0001)$. The drop in post-delivery hemoglobin $\geq 2 \mathrm{~g} / \mathrm{dL}$ after $48-72$ hours of delivery adjusted for predelivery hemoglobin was higher for carbetocin ( $p$ value $=0.0337$ ) although it was not clinically relevant.

A study done by Larciprete et al comparing the use of carbetocin versus oxytocin in caesarean section with high risk of postpartum haemorrhage showed that the post-partum drop in hemoglobin after 2 hours and 24 hours was similar in both the groups.17Another study done by Mark Boucher showed similar results wherein no significant difference was seen in the drop in haemoglobin and haematocrit values between the two groups receiving carbetocin and oxytocin after vaginal delivery [19].

Despite the slightly higher, but clinically insignificant, drop in post-delivery haemoglobin for HS carbetocin compared to oxytocin, the former offers advantage in being heat stable. Delayed diagnosis and treatment can lead to hypovolemic shock in women with severe postpartum haemorrhage. Hence, accurate measurement of blood loss and timely diagnosis and management can prevent avoidable morbidity and mortality associated with cases of severe post-partum haemorrhage [13]. The use of heat stable carbetocin would be a boon for prevention of post-partum haemorrhage in peripheral regions of low- and middle-income countries where constant maintenance of cold temperature for oxytocin is a difficulty.

Page 5/12 


\section{Conclusion}

Post-delivery hemoglobin unadjusted or adjusted for pre-delivery hemoglobin was slightly lower for carbetocin compared to oxytocin. Correspondingly, the drop in hemoglobin was slightly higher for carbetocin. The proportion of participants with a drop in hemoglobin of $2 \mathrm{~g} / \mathrm{dL}$ or more, both unadjusted and adjusted for pre-delivery hemoglobin, was higher for carbetocin. However, the magnitude of these differences was not clinically relevant. The present study also showed that there is a decrease in postdelivery hemoglobin with blood loss which was not significantly different between carbetocin and oxytocin groups. Based on results from the present study, measurement of drop in hemoglobin might be eventually used as a proxy for post-partum blood loss, provided further studies are conducted to shed more light on other individual factors that can improve individual prediction of blood loss, for assessing the efficacy of intervention for prevention and treatment of post-partum hemorrhage.

\section{Abbreviations}

PPH- Postpartum haemorrhage

HS- Heat stable

IQR- Interquartile range

RR- Relative risk

\section{Declarations}

\section{Competing interests}

The authors declare that they have no competing interests.

\section{Ethics approval and consent to participate}

This study was reviewed and approved by institutional ethics committee of KLE Academy of Higher Education and Research's Jawaharlal Nehru Medical College, Belagavi. All women provided informed consent for participation in the study.

\section{Consent for publication}

Not applicable

\section{Funding}

The main trial was supported by funding from MSD, through its MSD for Mothers program and is the sole responsibility of the authors. MSD for Mothers is an initiative of Merck \& Co., Inc., Kenilworth, NJ, U.S.A. The study was funded by KLE Academy of Higher Education \& Research.

\section{Authors' contributions}

SSV conceived of the manuscript and wrote the first draft with input from MSS, SSG, GP, JFC, AMG and MW. SSV, SSG, MM, YVP, AR, MSS and SSG oversaw study implementation, data collection and quality monitoring. GP and JFC performed the statistical analyses. All authors reviewed and approved the final manuscript.

\section{Availability of data and materials}

The datasets generated during and/or analysed during the current study are available in the World Health Organization repository. The link to datasets can be requested to Mariana Widmer at widmerm@who.int.

\section{Acknowledgements}


Not applicable.

\section{References}

1. WHO Fact sheets- Maternal Mortality, 2019. Available at https://www.who.int/news-room/fact-sheets/detail/maternalmortality

2. Say L, Chou D, Gemmill A, Tunçalp O, Moller A, Daniels J, Gülmezoglu A M, Temmerman M, Alkema L; Global Causes of Maternal Death: A WHO Systematic Analysis. Lancet Global Health 2014; 2: e323-33

3. WHO Recommendations for the prevention and treatment of postpartum haemorrhage. World Health Organization, 2018. Available at https://apps.who.int/iris/bitstream/handle/10665/277276/9789241550420-eng.pdf?ua=1

4. Gallos ID, Williams HM, Price MJ, Merriel A, Gee H, Lissauer D, Moorthy V, Tobias A, Deeks JJ, Widmer M, Tunçalp Ö, Gülmezoglu AM, Hofmeyr GJ, Coomarasamy A. Uterotonic agents for preventing postpartum haemorrhage- a network metaanalysis (Review). Cochrane Database of Systematic Reviews 2018, Issue 4. Art. No: CD011689. DOI: 10.1002/14651858.CD011689.pub2.

5. (WHO joint statement) WHO/UNICEF/UNFPA joint Statement - Appropriate Storage and Management of Oxytocin - a Key Commodity for Maternal Health. Available at: https://apps.who.int/iris/bitstream/handle/10665/311524/WHO-RHR-19.5eng.pdf

6. Oxytocin Injection-Clarification of stability data and storage statement requirements. Available at https://extranet.who.int/prequal/sites/default/files/documents/150\%20stability\%20data\%200xytocin\%200ct2018.pdf

7. Rath W. Prevention of postpartum haemorrhage with the oxytocin analogue carbetocin. Eur J Obstet Gynecol Reprod Biol. 2009 Nov; 147(1):15-20.

8. Su LL, Chong YS, Samuel M. Carbetocin for preventing postpartum haemorrhage. Cochrane Database Syst Rev. 2012 Apr 18; 4:CD005457. doi: 10.1002/14651858.CD005457.pub4.

9. Malm M, Madsen I, Kjellström J. Development and stability of a heat-stable formulation of carbetocin for the prevention of postpartum haemorrhage for use in low and middle-income countries. J Pep Sci. 2018; e3082, DOI: 10.1002/psc.3082

10. Widmer M, Piaggio G, Abdel-Aleem H, Carroli G, Chong YS, Coomarasamy A, Fawole B, Goudar SS, Hofmeyr GJ, Lumbiganon P, Mugerwa K, Nguyen TMH, Qureshi Z, Paulo Souza J, Gülmezoglu AM. Room temperature stable carbetocin for the prevention of postpartum haemorrhage during the third stage of labour in women delivering vaginally: study protocol for a randomized controlled trial. Trials 2016. March 2017; 17(1):143. doi: 10.1186/s13063-016-1271-y

11. Widmer M, Piaggio G, Nguyen TMH, Osoti A, Owa OO, Misra S, Coomarasamy A, Abdel-Aleem H, Mallapur AA, Qureshi Z, Lumbiganon P, Patel AB, Carroli G, Fawole B, Goudar SS, Pujar YV, Neilson J, Hofmeyr GJ, Su LL, Ferreira de Carvalho J, Pandey U, Mugerwa K, Shiragur SS, Byamugisha J, Giordano D, Gülmezoglu AM; WHO CHAMPION Trial Group.. Heat-Stable Carbetocin versus Oxytocin to Prevent Hemorrhage after Vaginal Birth. N Engl J Med. 2018 Jun 27. doi:

10.1056/NEJMoa1805489. [Epub ahead of print] PubMed PMID: 29949473

12. Bellad MB, Laxmi BV, Goudar SS, Ashwath Kumar. Standardized Visual Estimation of Blood Loss during vaginal delivery with its correlation Hematocrit Changes - A descriptive study. Journal of SAFOG; January-April 2009; 1 (1): 29-34

13. Anger H, Durocher J, Dabash R, Winikoff B. How well do postpartum blood loss and common definitions of postpartum haemorrhage correlate with postpartum anaemia and fall in hemoglobin? PLoS ONE. 2019; 14(8): e0221216. https://doi.org/10.1371/journal.pone.0221216

14. Raghavan S, Geller S, Miller S, Goudar SS, Anger H, Yadavannavar MC, Dabash R, Bidri SR, Gudadinni MR, Udgiri R, Koch AR, Bellad MB, Winikoff B. Misoprostol for primary versus secondary prevention of postpartum haemorrhage: a clusterrandomised non-inferiority community trial. BJOG. 2016 Jan; 123(1): 120-7. doi: 10.1111/1471-0528.13540. Epub 2015 Sep 1.

15. Larciprete G, Montagnoli C, Frigo M, Panetta V, Todde C, Zuppani B, Centonze C, Bompiani A, Malandrenis I, Cirese A, and Valensise $\mathrm{H}$ Carbetocin versus oxytocin in caesarean section with high risk of post-partum haemorrhage. J Prenat Med. 2013 Jan-Mar; 7(1): 12-18. 
16. Althabe F, Bergel E, Buekens P, Sosa C, Belizan JM. Controlled cord traction in the third stage of labor. Systematic review. Int J Gynaecol Obstet. 2006 Nov; 94 Suppl 2:S126-S127. doi: 10.1016/S0020-7292(06)60006-4

17. Vickers AJ, Altman DG. Analysing controlled trials with baseline and follow up measurements. BMJ 2001, 323:1123-1124.

18. Carvalho JF, Piaggio G, Wojdyla D, Widmer M, Gülmezoglu AM. Distribution of postpartum blood loss: modeling, estimation and application to clinical trials. Reproductive Health (2018) 15:199. https://doi.org/10.1186/s12978-018-0641-1

19. Boucher M, Nimrod CA, Tawagi GF, Meeker TA, Rennicks White RE, Vann J. Comparison of carbetocin and oxytocin for the prevention of postpartum haemorrhage following vaginal delivery: a double-blind randomized trial. J Obstet Gynecol Can 2004; 26: 481-8.

\section{Tables}

Table 1. Characteristics of Women at Trial Entry and at Labour, and of Babies at Birth: 


\begin{tabular}{|c|c|c|}
\hline Characteristics & $\begin{array}{l}\text { Carbetocin } \\
(\mathrm{N}=897)\end{array}$ & $\begin{array}{l}\text { Oxytocin } \\
(\mathrm{N}=898)\end{array}$ \\
\hline \multicolumn{3}{|l|}{ Age- $y r$} \\
\hline Median & 23 & 23 \\
\hline Interquartile range & 5 & 5 \\
\hline Nulliparous- number (\%) & $468(52.2)$ & $493(54.9)$ \\
\hline Previous miscarriages- number (\%) & $102(11.4)$ & $119(13.3)$ \\
\hline CS in previous deliveries ${ }^{1}$ - number (\%) & $21(4.9)$ & $26(6.5)$ \\
\hline Postpartum haemorrhage in previous pregnancies ${ }^{1}$ - number $(\%)$ & $0(0)$ & $1(0.2)$ \\
\hline Pre-delivery hemoglobin $(\mathrm{g} / \mathrm{dL})-\mathrm{n}$ & 895 & 898 \\
\hline Median & 11.2 & 11.2 \\
\hline Interquartile range & 1.6 & 1.8 \\
\hline Gestational age (completed weeks)- $\mathrm{n}$ & 897 & 898 \\
\hline Median & 39 & 39 \\
\hline Interquartile range & 2 & 2 \\
\hline Labour induced- number (\%) & $155(17.3)$ & $142(15.8)$ \\
\hline Labour augmented- number (\%) & $167(18.6)$ & $160(17.8)$ \\
\hline Instrument-assisted vaginal birth- number (\%) & $34(3.8)$ & $34(3.8)$ \\
\hline Perineal trauma leading to suture- number (\%) & $829(92.4)$ & $833(92.8)$ \\
\hline Baby alive- number (\%) & $849(94.6)$ & $850(94.7)$ \\
\hline Sex male ${ }^{2}-$ number (\%) & $446(49.7)$ & $453(50.5)$ \\
\hline Birthweight (grams)- $n$ & 897 & 898 \\
\hline Median & 2800 & 2800 \\
\hline Interquartile range & 610.0 & 600.0 \\
\hline \multicolumn{3}{|l|}{ Occupation: } \\
\hline Home-maker- number (\%) & $883(98.4)$ & $884(98.4)$ \\
\hline \multicolumn{3}{|l|}{ Education: } \\
\hline Illiterate- number (\%) & $35(3.9)$ & $47(5.2)$ \\
\hline
\end{tabular}

1 Two values are missing for CS and Postpartum haemorrhage in previous pregnancies in the Oxytocin group 2 One missing value for sex of baby in the Oxytocin group

Table 2. Mean Predelivery and Post-Delivery Hemoglobin, Mean Drop in $\mathrm{Hb}$ and Median Postpartum Blood Loss - Univariate Unadjusted Analysis: 


\begin{tabular}{|lllll|}
\hline Outcome & $\begin{array}{l}\text { Carbetocin } \\
\mathbf{N}=\mathbf{8 9 0}\end{array}$ & $\begin{array}{l}\text { Oxytocin } \\
\mathbf{N}=\mathbf{8 8 9}\end{array}$ & Difference or ratio (95\%Cl) & p-value \\
\hline Pre- delivery Hemoglobin (g/dL, mean, difference) & 11.3 & 11.3 & $-0.014(-0.136$ to 0.107$)$ & 0.8169 \\
\hline Post- delivery Hemoglobin (g/dL, mean, difference) & 10.09 & 10.21 & $-0.128(-0.251$ to -0.004$)$ & 0.0432 \\
\hline Drop in Hb (g/dL, mean=median, difference) & 1.2 & 1.1 & $0.117(-0.013$ to 0.248$)$ & 0.0786 \\
\hline Postpartum blood loss (mL, median, ratio) & 160.4 & 163.2 & $0.98(0.92$ to 1.05$)$ & 0.6214 \\
\hline
\end{tabular}

Table 3. Primary Outcome: Effect of Treatment on Post-delivery Hemoglobin ( $g / d L)$ adjusted for Pre-delivery Hemoglobin (Model 1) and adjusted for Pre-delivery Hemoglobin and Blood Loss (Model 2) - Analysis of Covariance:

\begin{tabular}{|llllll|}
\hline Model & \multicolumn{4}{l}{ Mean post-delivery hemoglobin $(\mathrm{g} / \mathrm{dL})$} & \multicolumn{4}{l|}{ Effect of treatment: Difference of means Carbetocin minus Oxytocin } \\
\cline { 2 - 6 } & Carbetocin & Oxytocin & Difference & $95 \%$ Cl & p-value \\
\hline Model 1 & 10.09 & 10.21 & -0.12 & -0.23 to -0.01 & 0.0334 \\
\hline Model 2 & 10.09 & 10.22 & -0.13 & -0.24 to -0.02 & 0.0257 \\
\hline
\end{tabular}

Table 4. Secondary outcome: proportion of women with a drop in post-delivery hemoglobin $\geq 2 \mathrm{~g} / \mathrm{dl}$ after $48-72$ hours of delivery (mITT Population):

\begin{tabular}{|c|c|c|c|c|c|c|c|c|c|c|c|c|c|}
\hline & \multicolumn{3}{|c|}{ CARB } & \multicolumn{10}{|l|}{ OXY } \\
\hline & $n$ & $\mathbf{N}$ & $\%$ & $n$ & $\mathbf{N}$ & $\%$ & $\mathrm{RR}$ & $\begin{array}{l}\text { Lower } \\
\text { CL }\end{array}$ & $\begin{array}{l}\text { Upper } \\
\text { CL }\end{array}$ & $\begin{array}{l}\mathrm{p}- \\
\text { value }\end{array}$ & $\begin{array}{l}\text { Risk } \\
\text { Difference } \\
\%\end{array}$ & $\begin{array}{l}\text { Lower } \\
\text { CL }\end{array}$ & $\begin{array}{l}\text { Upper } \\
\text { CL }\end{array}$ \\
\hline $\begin{array}{l}\text { Drop in } \mathrm{Hb} \\
\geq 2 \mathrm{~g} / \mathrm{dL} \\
\text { unadjusted }\end{array}$ & 248 & 890 & 27.9 & 214 & 889 & 24.1 & 1.16 & 0.99 & 1.36 & 0.0682 & 3.79 & -0.28 & 7.86 \\
\hline $\begin{array}{l}\text { Drop in } \mathrm{Hb} \\
\geq 2 \mathrm{~g} / \mathrm{dL} \\
\text { adjusted } \\
\text { for pre- } \\
\text { delivery } \mathrm{Hb}\end{array}$ & - & & & & & & 1.29 & 1.02 & 1.63 & 0.0337 & 3.89 & 0.16 & 7.61 \\
\hline
\end{tabular}

\section{Figures}




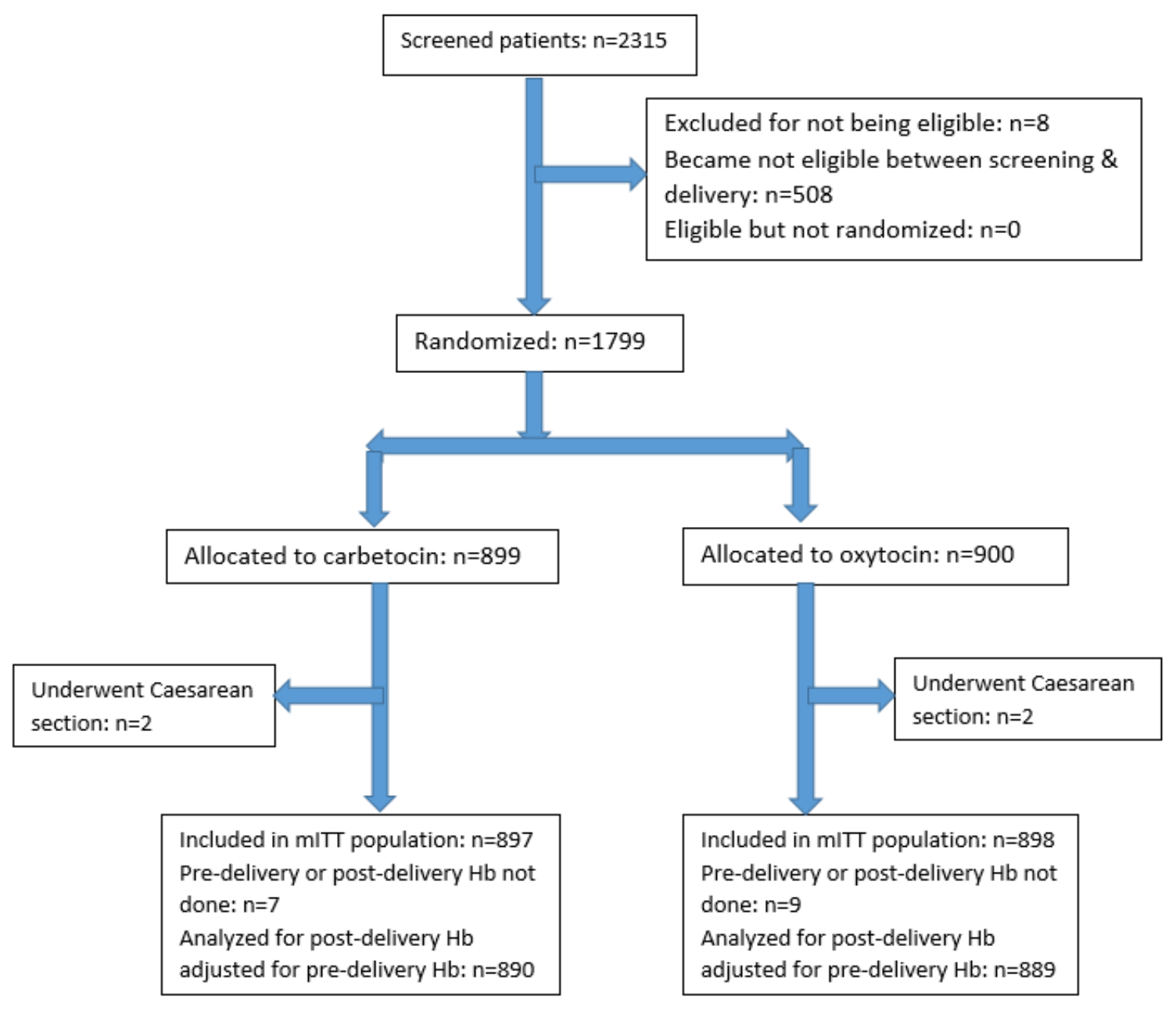

Figure 1

Trial profile of study participants 


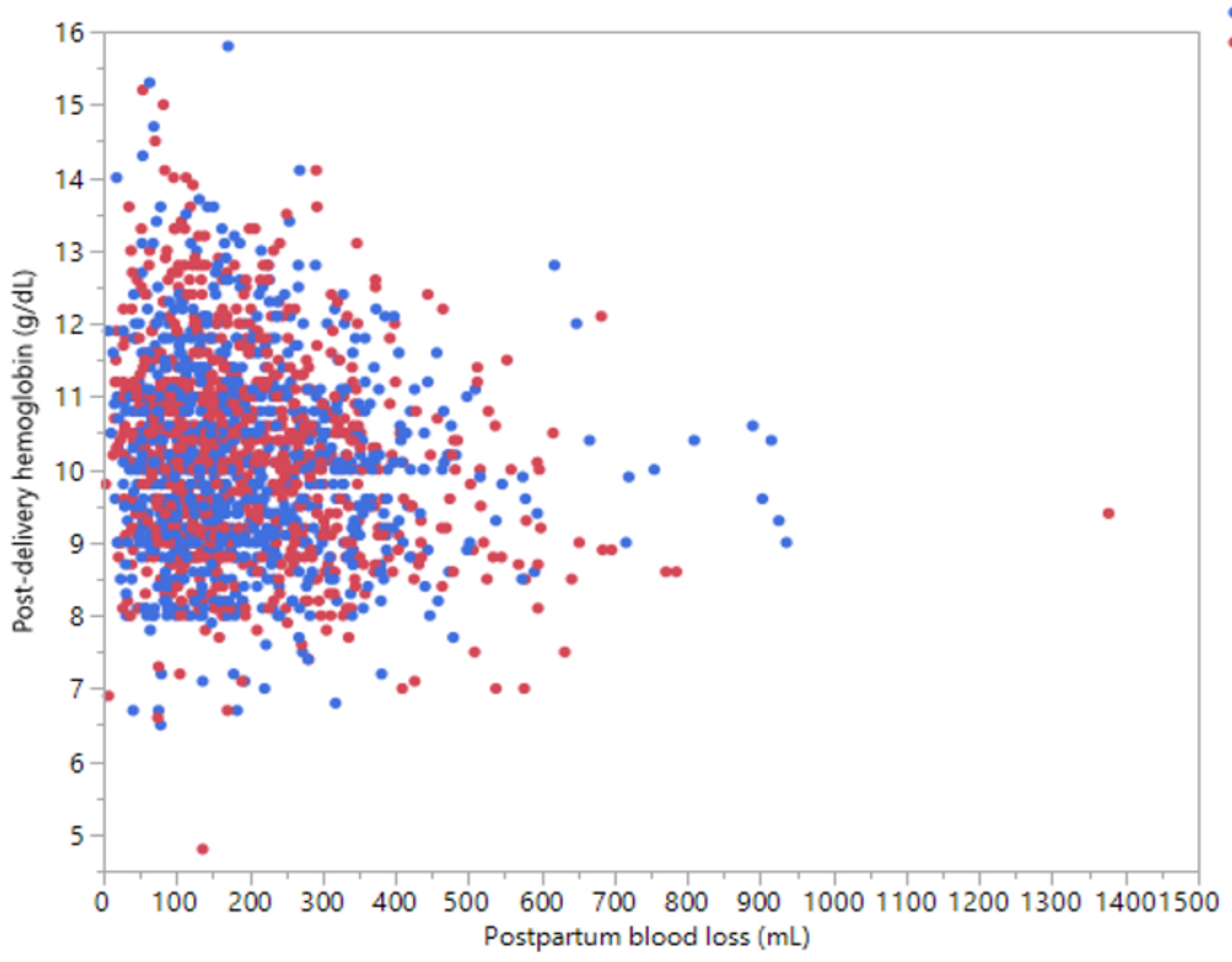

- Carbetocin

- Oxytocin

Figure 2

Plot of post-delivery hemoglobin $(\mathrm{g} / \mathrm{dL})$ versus blood loss $(\mathrm{mL})$, by treatment: 